\title{
A child's day: trends in time use in the UK from 1975 to 2015
}

Killian Mullan

\begin{abstract}
This paper examines change in school-age children's (8-16 years) time use in the United Kingdom between 1975 and 2015. Over this period, concerns for children's safety, technological change, and increased emphasis on success in school are widely argued to have altered children's daily lives, leading for example to less time outdoors, more time in screenbased activities, and more time focused on education. Using data from three national time use surveys collected in 1974-5, 2000-01 and 2014-15, this paper explores the extent to which these arguments reflect actual change in how children spend their time throughout the day. The results show that between 1975 and 2015 children increased their time at home, and spent more time in screen-based activities and doing homework. Decreases in time in out-ofhome activities were concentrated in time in unstructured play, partially offset by increased time in sport. A decomposition of trends revealed that, despite a narrowing of the gender gap in time in housework, gender remains a significant factor determining many aspects of children's time use. In contrast, the significance of age declined in most leisure activities, with the exception of screen-based activities where significant age differences emerged in 2000 and widened further in 2015.
\end{abstract}

Key words: children; time use; social change; gender; United Kingdom Time Use Survey 


\section{Introduction}

This paper examines trends in children's time use in the United Kingdom (UK) between 1975 and 2015. Over this period, it is widely held due to ongoing parental concerns for their safety, together with rapid technological change, that children are less active, spending more time indoors in screen-based activities, with their time outside the home increasingly focused on structured, supervised activities. Added to this, with educational attainment now pivotal for later outcomes, pressures on children to succeed in school have intensified in recent decades. In tandem, there are worsening trends in some physical and mental health outcomes for children over this period, with these often linked to supposed changes in children's daily lives.

Yet we lack a thorough study of long-term change in children's daily lives in the UK. Previous research in the UK addresses change in children's daily lives only with reference to certain activities, over limited time spans. Absent from the literature is an analysis of longterm change across the full spectrum of activities making up a child's day. We know little therefore about the extent to which widespread views about change in children's daily lives, touching on a range of different activities, reflect actual change in the varied ways they spend their time throughout the day. Addressing this, this paper presents the results of an analysis of change in school-aged children's time use (aged 8-16 years) using data from three nationally representative time use survey collected in 1974-75, 2000-01 and 2014-15. The paper also examines the extent to which trends are similar for boys and girls, and for children in different age groups, thereby investigating change and stability in the influence of gender and age on children's daily activities over time. 


\section{The demise of an active childhood?}

The active playful child is an enduring image of childhood (Wyness, 2006), but some argue that children's daily lives, over the past several decades, have become less active, and more confined to the home (e.g. Gill, 2004; Hillman et al. 1990; Valentine, 2004). One oft-cited reason for this is that parental concerns for children's safety have heightened over time (Furedi, 2005; Valentine, 1997). The argument here is not that children today are objectively in more danger now than they were in previous decades. Rather that there is a generalised culture of fear and risk aversion, a sense that over recent decades the world has become a more dangerous place for children, influencing the decisions parents make about time their children spend outdoors, often coinciding with time when they are unsupervised (Kelly et al., 1998).

Although the view that parents have become more concerned about their children's safety over time is commonplace, there are no studies of change over time that directly measure parental concerns for children's safety. Shaw et al. (2013) present data on children's independent mobility from surveys conducted in 1971, 1990 and 2010, but questions relating to parental concerns about safety in the local neighbourhood were available for 2010 only. Nevertheless, Shaw et al. (2013) show that parents spontaneously cite concerns about neighbourhood safety in relation to the restrictions they place on their children's independent mobility, and studies continue to demonstrate that parental concerns about safety impinge upon children's play outside the home (e.g. Faulkner et al., 2015).

If concerns for children's safety have pushed them indoors, arguably simultaneously expanding options for home-based leisure afforded by rapid technological change have pulled 
them in the same direction. In the mid-1970s TV was the dominant media technology occupying children's leisure time indoors (Livingstone, 2009a). By the turn of the millennium, TV was already competing with other devices, such as videogame consoles and computers, for children's time in the home (Livingstone, 2002). From the millennium onwards, home-ownership of computers increased dramatically from $44 \%$ in 2000 to $83 \%$ in 2014 (ONS, 2002; ONS, 2014), and over 90\% of children in the UK now access the internet at home (Ofcom, 2015). Increased access to, and use of, multiple new technologies, along with concern for children's safety, may have led to children spending more time in screenbased activities indoors than in the past (Palmer, 2007).

Running alongside this are concerns about the health impacts of children leading less active lives (PHE, 2013). Excessive time in sedentary, screen-based activities has been implicated as one possible factor underpinning rising levels of childhood obesity and associated health conditions (Hills et al., 2011). Consequently, public health campaigns seek to promote children's engagement in sport and other physical activity (NICE, 2009). However, taking into consideration general concerns for children's safety, these efforts may act to funnel children towards organised, typically supervised, physical activity such as sport.

Education has long been a prominent feature of children's daily lives, but some argue that children have become increasingly oriented towards success in education and their future outcomes (Ennew, 1994; Prout, 2005). Gathering pace from the 1970s onwards, successive governments initiated major reforms to education to raise standards and attainment (Machin and Vignoles, 2006). In the late 1980s, the National Curriculum introduced formal assessment at 'key stages' starting in primary school from age 6-7 years, and with additional coursework requirements for secondary school pupils (excluding Scotland). Children across 
the UK now take compulsory tests for literacy and numeracy in primary school, and the Education and Skills Act 2008 raised the school-leaving age to 18 (if not employed).

Children therefore may be spending more time in school-related activities such as homework or study. Indeed, the New Labour Government in the late 1990s stressed the importance of homework in promoting children's educational success, including setting recommendations for the time children should spend doing homework (DfEE, 1998). Added to this, levels of educational attainment among adults have increased over the past several decades (Halsey, 2000), that may lead to increasing time in homework as this is positively associated with higher parental education (Bianchi and Robinson, 1996).

Changes in children family contexts over the past several decades also may influence their daily activities. Children increasingly live in dual-earner families (ONS, 2015), are more likely to live in lone-parent families, and have fewer siblings (ONS, 2009). These changes affect who children spend time with in the family, and directly touch on issues relating to their supervision as more parents seek to balance work and family commitments. These changes might affect children's time in relatively protective environments such as the home, or in structured, supervised, activities outside the home. It is therefore important to account for compositional change in children's family contexts when considering trends in their daily activities.

Parental concerns for children's safety and technological change might be leading children to spending more time indoors, focused on screen-based activities. In addition, they may be spending less time in unstructured play outside the home, and more time in organised, supervised activities like sport, while the increasing importance of education may lead children to spend more time doing homework. Taken together, these factors may be resulting 
in children leading less active, more home-based lives, increasingly oriented towards education. Some limited evidence as to whether this is the case may be gleaned from previous research on trends for certain activities.

\section{Trends in children's daily activities: Prior research}

It is almost a truism to state that children's play outside the home has declined, but this is based largely on parents' reports of having spent more time playing outdoors than their children and small-scale studies in particular communities (Karsten, 2005; Lacey, 2007; Loebach and Gilliland, 2016; McNeish and Roberts, 1995; Valentine and McKendrick, 1997). These studies provide key insights into trends in children's play outdoors, but to date no prior research examined long-term change in children's time playing both at home and elsewhere in the UK using nationally representative data.

Finch (2002) suggests that increased engagement in organised sport might offset decreases in outdoor play. There is some data to support the view that children in the UK have increased their participation in sport since the 1980s (Dallman, Norton, and Norton, 2005). Data from the Taking Part Survey (DCMS, 2015) show that the proportion of 5-10 year olds participating in sport during a week dropped from $75 \%$ in $2008 / 09$ to $69 \%$ in $2014-15$, whereas a consistent $90 \%$ of children 11-15 years participated in sport in the week prior to interview in these years. Although general questions about participation in sport are broadly informative, it is not possible to combine them with measures from separate studies of children's engagement in other activities like play. As a result, previous research tells us nothing about whether children's daily time in play and sport together increased, decreased, or remained stable. 
Turning to TV and other screen-based activities, Marshall et al. (2006) find no change in children's TV viewing across the latter half of the twentieth century, though recent data suggests that technological change since 2000 has affected children's time in screen-based activities. In the decade up to 2015 , Ofcom (2016) reports a modest decline in the time children 5-15 years spend watching TV, along with substantial increases in the time children spend playing videogames, and using computers and the internet, suggesting an increase in total time in screen-based activities. However, Ofcom ask children to recall how much time they spend in screen-based activities on a typical day, which can be unreliable (Robinson, 1985). Moreover, we cannot combine responses to questions for different activities to obtain a measure of total time in screen-based activities. Therefore, we know little about long-term change in children's total time in screen-based activities, nor about how this connects with long-term trends in children's time in other activities such as play and sport.

Increases children's time in homework are expected given the increased importance of education for children's outcomes, but data on children's daily homework time in the UK are extremely limited (see Weston, 1999). Mullis et al. (2004; 2015), using recall-based measures, report that the proportion of children 13-14 years in England engaging in maths homework for around 1-3 hours per week fell from 37\% in 2003 to $26 \%$ in 2015 (a similar decrease was found for science homework). However, no previous research has presented reliable data on long-term trends in children's time in homework across all subjects. It is also worth noting here that in addition to school-related work, we know very little about long-term trends in the daily time children commit to housework and paid work. 
Extant research offers patchy evidence that children's lives have become less active, more home-based and screen-focused, with more structured leisure like sport and less unstructured play outdoors. Clearly absent however is a comprehensive study of long-term trends across a full range of activities that make up a child's day, using comparable measures from nationally representative data. Data from time use surveys are especially valuable in this regard. National time use surveys collect reliable data on the amount of time people spend in different activities throughout the day (Gershuny, 2000), and are a key source of information concerning children's daily lives (Ben-Arieh and Ofir, 2002). As they provide information about children's time for all the activities they engage in throughout the day, using the same metric (minutes per day), they allow us to study change over time for different activities. Finally, being large-scale surveys they allow for the analysis of trends for different groups of children. This paper uses data from three nationally representative UK time use surveys to examine trends in children time use between 1975 and 2015, adding the UK to a small body research looking at trends in children's time use in different countries (for the USA see Hofferth and Sandberg, 2001 and Hofferth, 2009; for Italy (Turin) see Carriero, 2006).

\section{Research focus}

Against rising concerns for children's safety, technological change, and the increasing importance of education over the past several decades, this paper explores the extent to which change in children's time use might support arguments that children's daily lives have become less active, more oriented towards time at home, and more focused on their education. We address this through a multivariate regression analysis of trends in children's time use using three surveys collected in 1975, 2000, and 2015, exploiting information on what children are doing and where they are throughout the day. Combining information about 
the full range of children's activities throughout the day together with their location allows us to explore, further than any previous research, whether children's lives in the UK, over the past several decades, have become less active, more home-based, and more oriented to their education.

Further to studying overall trends in children's time use, the paper examines the extent to which trends vary for boys and girls, and for children in different age groups. Parents' concerns for children's safety differ for boys and girls, and for children of different ages (Valentine, 1997; 2004). The possible influence of technological change may also vary by gender and age, as these are key factors associated with children's use of media and technology (Hofferth, 2010; Livingstone, 2002; 2009b), and the pressures and requirements of education certainly intensify as children get older. In disaggregating trends by gender and age, the paper examines change over time in the influence of these factors on children's time use. In doing so, it considers whether changes in children's time use might be tied to changing gender roles (Oakley, 2015), as well as changes in age-related expectations for children that are embedded in social constructions of childhood (James, Jenks, and Prout, 1998).

\section{Methods}

\section{Data and Sample}

The analysis uses data provided by children aged 8-16 years living in residential households with their parents, from three national UK time use surveys from 1975, 2000, and 2015. Each of these surveys obtained representative samples of the population of UK residential households using a multi-stage cluster stratified sample design. The 1975 survey, conducted 
by the British Broadcasting Corporation (BBC), did not sample from Northern Ireland. In all surveys, all persons in the household, including children, completed time diaries reporting, in their own words, their main activities and location throughout the day, which were then coded using a specified activity code frame (see below). Studies of coder reliability carried out for the 2000 and 2015 surveys found high levels of coder agreement. ${ }^{i}$ No details are available on any study of the reliability of the coding process for the BBC 1975 survey. Time diary surveys typically ask respondents to complete time diaries for multiple days, and the unit of analysis is therefore a 'person-day' (Gershuny, 2000). Respondents to the 1975 BBC survey completed diaries for an entire week (seven days), and respondents to the 2000 and 2015 surveys completed diaries for one weekday and one weekend day (two days). Therefore, there are multiple observations for each child in the sample. Data from two of the possible seven diary days were retrieved from the BBC archive for approximately one quarter of respondents in the 1975 survey. A small proportion of children in the 2000 and 2015 surveys provided a single diary only ( $5 \%$ and $3 \%$ respectively).

Diaries from teenagers 15-16 years who were not students were dropped $(n=173)$, as were diaries with more than four hours of unreported time $(n=119)$. As information from mothers is incorporated in the analysis (see below), cases where this information was missing were not included in the analysis sample. The extreme cases are those where no information about the mother was available. In the 2000 and 2015 surveys this affected only a small proportion of cases ( $n=22$ and $n=8$ respectively), but 401 cases from the 1975 BBC survey $(11.5 \%$ of the 1975 sample) were dropped because there was no data from the child's mother. We do not know whether these mothers were non-respondents, or whether this data was lost. A further 237 cases were dropped because some information from the mother was missing, mostly from the 2000 survey $(n=169)$. There were no significant differences in time in the activities 
measured here (see following section) between children included in the analysis sample and those who were not because some or all of the data from their mothers was missing (results available on request). The final analysis sample has 7958 cases. Table II below provides information about the characteristics of children included in sample.

A key indicator of diary quality is the amount of time with no activity reported, and the data provided by children are of similar quality to those provided by adults in this regard. Diaries from children 8-16 years have an average 18.6 minutes unreported time compared with 17.8 minutes in diaries completed by those aged $17+$ years, although the youngest children $8-10$ years average slightly more unreported time (3 minutes) than both older children (11-16 years) and adults.

\section{Measures of children's time use}

There are two sets of measures of children's time use, all measured in minutes per day, which together provide a complete picture of a child's day. The first set of measures corresponds to activities at home or that take place indoors. The second corresponds to out-of-home or outdoor activities. Information about whether the activity took place at home or not is used to make the distinction between home/indoor activities and out-of-home/outdoor activities. Note that whether or not the respondent was at home is the only information about location collected in the BBC 1975 survey. When children report being at home they could be indoors or outdoors (in the garden for example), and similarly time not at home could be indoors or outdoors. Therefore, information about the activity is used in conjunction with location information (at home or not) to construct measures of time (minutes) in home/indoor activities and out-of-home/outdoor activities. Table I provides a summary of the activities analysed in the paper. 


\section{[TABLE I ABOUT HERE]}

Home/indoor activities consist of time (minutes) doing homework or study, housework, socialising, play, hobbies, and screen-based activities when the child reports being at home. Note that a small amount of time in homework, hobbies, and screen-based activities took place somewhere other than at home, but these are typically indoor activities and treated as such here. Out-of-home/outdoor activities consist of time (minutes) doing paid work, shopping, socialising, play, sport and exercise, and religious and civic activities when the child reports not being at home. All measures of out-of-home/outdoor activities include any travel associated with the respective activity. A small amount of time in paid work, sport and exercise, and religious and civic activities occurs when children report being 'at home'. The results are insensitive to the inclusion/exclusion of this time, and all time in these activities is included in the out-of-home/outdoor activities measures for completeness. Measures of total minutes in home/indoor and out-of-home/outdoor activities were created to examine change in overall time in these activities. Lastly, measures of necessary time (sleep, eating, personal) and time at school (including travel to/from school) round out children's time at home/indoors and out-of-home/outdoors respectively providing a comprehensive overview of a child's entire day.

Note that children's time in out-of-home/outdoor activities excludes time when they are at school. School is a highly structured and protected environment for children, and thus not likely a source of parents' concerns for children's safety, nor is time at school likely to be directly influenced by technology in the family home. There may be changes in the way children spend time at school, perhaps tied to education reforms, but this lies outside the 
scope of this paper. Note also however that activities taking place at school after classes have finished are treated as out-of-home activities not as time 'at school'. This reflects the fact that extra-curricular activities can take place in schools after the formal school day has finished.

The UK Time Use Surveys in 2000 and 2015 used an almost identical activity code frame based on Harmonised European Time Use Survey (HETUS) guidelines (Eurostat, 2009), specifically designed to ensure comparability of time-use measures both across countries and over time. Therefore, the basic harmonisation task involved converting the activity code frame in the BBC 1975 survey to correspond with the HETUS activity codes. The BBC code frame is simpler than the HETUS code frame. For example, the BBC code frame contains a single code for 'sport', where the HETUS code frame contains specific codes for different types of sport. Therefore, detailed codes in the later surveys are collapsed into broader activity categories to be comparable with activity codes in the BBC survey. Full details about the harmonisation of the BBC and HETUS activity code frames are contained in Appendix 1.

\section{Statistical analysis and independent variables}

The measures of time in different activities set out above are the dependent variables in OLS regression models. A first set of models analyses change in children's time use. Using data from the three surveys, the analysis studies change across three periods: 1) between 1975 and 2000; 2) between 1975 and 2015; and 3) between 2000 and 2015. This design allows us to observe whether any change is concentrated in the earlier period (1975-2000) or later period (2000-2015) only, or over both periods. As noted earlier, technological change has been especially rapid in the later period, and this design provides for a limited exploratory analysis of the impact of this as distinct from other factors such as concerns for children's safety and educational change, any effects of which we might observe over a longer time span. The 
main effects for survey year capture change for the first and second of these periods, while change between 2000 and 2015 is assessed using post-regression tests for differences between the coefficients for survey years 2000 and 2015 .

A second set of models disaggregates trends for boys and girls, and for children in different age groups, by including interactions between survey year, and child gender (boy $=0$ [reference]; girl $=1)$ and age $(8-10$ years $=0$ [reference]; $11-13$ years $=1$, and $14-16$ years $=2)$ respectively. Here the focus will be on the main effects for gender and age, and the interaction effects between these characteristics and survey years. Recall that children completed multiple diaries introducing some dependence (relationship) between cases, violating the OLS assumption that cases are independent. Therefore, significance tests in all models use clustered standard errors that are robust to violation of the independence assumption.

All models control for maternal employment status (employed 'full-time' or 'part-time' compared with 'not in paid work') and education level. To control for maternal education, the models include a dummy variable that identifies mothers who remained in education beyond the modal age of having left full-time education for mothers in the sample in each survey year. This was at age 15 in 1975, 16 in 2000, and 18 year in 2015, reflecting the lengthening of time in effective compulsory education over this period. Models also control for family size and structure. Family structure refers to whether children live in a lone mother household or live with both their mother and father (the reference category). In 1975, this measure is constructed using responses to a question about the whether the child's father is absent/deceased. In 2000 and 2015, information taken from a household grid identifies 
children not living with a co-resident father. Finally, the models control for whether the diary day was a school or non-school day.

Table II provides information on the characteristics of the sample. As expected, average family size decreased over time, and the proportion of children in lone-mother families increased substantially over time, with no change between 2000 and 2015 (ONS, 2009; ONS, 2016). Given the marked increase in lone-mother families, models were estimated for a restricted sample of children in two-parent families, and the results for change over time were substantively equivalent to those reported in the paper for the entire sample (results available on request). The sample also reflects the increase in educational attainment of mothers, though measured here broadly. The percentage of employed mothers is relatively stable, which does not accord with increases in maternal employment over this period. In the mid1970 s, $65 \%$ of women $35-44$ years with two dependent children were employed in paid work (OPCS, 1974), while around $80 \%$ of mothers with dependent children 11-15 years were in paid employment in both 2000 and 2014 (ONS, 2015a). Children with employed mothers are therefore modestly underrepresented in the later surveys.

[TABLE II ABOUT HERE]

\section{Results and discussion}

The results are set out in two sections. Section 1 contains the results for overall trends in children's time use, beginning with the results from the models for children's time in home/indoor activities, followed by the results for their time in out-of-home/outdoor activities, and the results for the control variables in both sets of models. Section 2 presents 
the results of the analysis disaggregating trends by child gender and age. Unless otherwise stated, all results pertaining to change over time (increases or decreases) mentioned in the text are statistically significant $(\mathrm{p}<0.05)$, and 'no change' means no statistically significant change.

\section{Change in children's time use: 1975 to 2015}

\subsection{Change in children's home/indoor activities}

Table III reports the results from the models of children's time in home/indoor activities, total time in these activities, and total time in necessary/personal activities. Looking first at change during the 1975-2000 period, children spent more time doing homework in 2000 than their counterparts in 1975. Though expected, this increase is modest at just over quarter of an hour, so education has far from come to dominate children's time outside school. There was no change in children's time in play and socialising at home, but children spent less time in housework (-9.3 minutes) and hobbies (-16.9 minutes), and more time in screen-based activities (12.8 minutes) in 2000 compared with their counterparts in 1975.

Looking at the total time in home/indoor activities during this period, surprisingly there was no change suggesting that parental concerns about children's safety that were seemingly heightened around the turn of the millennium had little impact on the overall time children spent at home. Instead, we see an emerging division of time at home between 1975 and 2000 with more homework on the one hand, and more screen-based activities on the other, which likely reflects the rising influence of education and technology in children's daily lives over this period. 


\section{[TABLE III ABOUT HERE]}

Between 2000 and 2015, there was no change in children's homework time, with children in 2015 continuing to spend more time in this activity than those in 1975. The lack of change in children's homework time in this latter period is surprising considering that the pressures on children to succeed in education arguably have intensified, (with the introduction of compulsory testing in primary schools and the raising of the school-leaving age), so further increases in homework time in this period might have been expected. It does however correspond with data showing no increase in children's time doing mathematics homework (Mullis et al. 2003; 2015).

Children in 2015 spent less time in play and more time socialising at home than children in both 1975 and 2000. They also spent less time in hobbies and more time in screen-based activities than children in both 1975 and 2000, with change in the latter activity being substantially larger. Children in 2015 spent 22.4 minutes more in screen-based activities than those in 1975, almost double the difference found between 2000 and 1975, reflecting a significant increase in screen-based activities between 2000 and 2015. The influence of changing technology since 2000 , especially in the decade up to 2015 , is most likely to be a significant factor underpinning these trends. Note however that these trends exclude children's time using mobile devices, which a separate study considers.

This increase in screen-based activities largely accounts for the increase in children's total time in home/indoor activities in 2015 compared with 1975 (11.9 minutes), though this was not significant. Note, however, that children spent more time in sleep/personal activities in 2015 compared with 1975 (concentrated in sleep). Therefore, children's overall time at home 
(awake or asleep) increased by 22.3 minutes, implying that time away from home decreased, which is shown to be the case in the next section. To the extent that increasing time in screenbased activities displaced time in out-of-home/outdoor activities from 2000 onwards, these results imply that recent technological change is increasingly drawing children indoors, and that, consequently, children's daily lives have become less physically active than in the past. Before broaching this, however, we turn now to examine trends in children's time in out-ofhome/outdoor activities.

\subsection{Change in children's out-of-homeloutdoor activities}

Table IV reports the results from the models of children's time in out-of-home/outdoor activities (occurring outside school), total time in these activities, and total time at school. Children spent less time in paid work in both 2000 and 2015 than in 1975, though the difference was significant for the latter year only. Paid work, along with housework and homework together comprise time in what may be termed committed activities that in various ways can develop children's skills and sense of responsibility (Larson and Verma, 1999).

Viewed together, the decrease in time in paid work and housework, along with the increase in time in homework, serve to underscore the rising, increasingly singular, dominance of education with respect to children's time in committed activities.

In contrast to decreasing time in housework, between 1975 and 2000 children's time shopping and doing other domestic activities outside the home increased. Changes in shopping overwhelmingly drive this trend (results not shown), reflecting the influence of the growth in consumer culture in children's daily lives (Buckingham, 2011). Lastly, between 1975 and 2000, children's time in out-of-home/outdoor play decreased, while their time in sport and civic activities increased. The increase in sport offset the decrease in out-of- 
home/outdoor play such that there was no change in total time in these activities between 1975 and 2000.

As with total time at home/indoors, there was no difference in total time in activities beyond the home between 1975 and 2000. It is evident, however, that over this period children's time in out-of-home/outdoor activities was less composed of relatively unstructured and perhaps unsupervised activities such as play and socialising, with more time in structured physical activity (sport), and in activities where other adults are likely to be present, or in relatively structured environments (shopping; religious and civic activities). This move away from unstructured activities outside the home is broadly in accord with studies from other countries (Hofferth and Sandberg, 2001; Carriero, 2006).

\section{[TABLE IV ABOUT HERE]}

Unlike the 1975-2000 period, there was a significant decrease in total time in out-ofhome/outdoor activities in 2015 compared with 1975 (-21 minutes). Moreover, the coefficient for 2015 was significantly lower than for 2000 (5.6 minutes) indicating that total time in outof-home/outdoor activities decreased significantly between 2000 and 2015 . Children in 2015 still spent more time shopping than those in 1975 (7.6 minutes), but the size of this coefficient decreased significantly reflecting a decrease in time in this activity between 2000 and 2015. The change in time shopping in this latter period may be in response to changing economic conditions in these years, with economic growth around the turn of the millennium contrasting with a relatively weaker economy following the financial crisis from 2007 onwards. The rise in internet shopping is probably another factor at play here (ONS, 2015). Together, changes in paid work, shopping, and civic activities account for around half of the 
decrease in total time in out-of-home/outdoor activities, with the decrease in shopping being especially predominant.

For leisure activities beyond the home, there was no change in socialising and sport between 2000 and 2015, but there was a further substantial decline in children's time in out-ofhome/outdoor play (and consequently a decrease in total time in sport and out-ofhome/outdoor play). Other things equal, children averaged close to 30 minutes less time in out-of-home/outdoor play in 2015 than in 1975, which was significantly larger than the difference in the $1975-2000$ period (17.3 minutes)

Therefore, the decline in out-of-home/outdoor play was a major component of the shrinking of total time in out-of-home/outdoor activities between 2000 and 2015. There is no evidence that parents' worries for their children's safety in the UK appreciably heightened between 2000 and 2015, but this period has witnessed profound technological change. Moreover, as shown above, children's time in screen-based activities increased further over this same period. However, to recall from above, the downward trend in out-of-home/outdoor play (and the upward trend in screen-based activity) predates the substantial and rapid technological change occurring in the decade up to 2015. It might be that generalised concerns for children's safety have coalesced with technological change leading to a structural shift, albeit small, and over many decades, in children's daily lives characterised by increased time in home-based, sedentary activities.

\subsection{Control variables}

Before moving to further analysis of trends over time for boys and girls, and for children in different age groups, we now consider the results for the control variables in the models. 
First, note that the trends found here in all activities are robust to the inclusion of controls for maternal/family characteristics. The lack of sensitivity to controls stands in partial contrast to Hofferth and Sandberg's (2001) study of trends in US children's time use, where they found some connections between trends in children's time use and demographic change. Their study was of younger children 3-12 years whose time use may be more sensitive to demographic change, given their relatively high dependence on direct parental care, compared with the older school-age children 8-16 years studied here.

Maternal employment had little impact on children's time use, except that children with employed mothers spent less time in necessary/personal activities, more time in housework, and more time in paid work, but maternal employment was not significantly associated with total time in home/indoor or out-of-home/outdoor activities. Children in larger families spent more time in out-of-home/outdoor play, and more time in housework but less time shopping, though again there was no difference in total time in home/indoor or out-of-home/outdoor activities. There were a number of significant results connected to children's socio-economic status. Children with relatively highly-educated mothers spent less time in screen-basedactivities, spent more time doing homework, in civic activities, and slightly more time at school (8.3 minutes). They also spent more time in hobbies and less time in out-ofhome/outdoor play. Conversely, children in lone-mother households spent less time doing homework, housework and in hobbies, and more time in sleep/personal activities than those living with both a mother and father. Beyond the home, children in lone-mother families spent more time in play and social activities, and slightly less time at school (-4.7 minutes).

That trends overall are robust to the inclusion of these controls in the models shows that they apply equally to children across social groups. This does not preclude further analysis of the 
influence of socio-economic status, or other factors, on children's time use over time, but the remainder of this paper concentrates on findings relating to child gender and age, for which substantial and significant differences in time use trends were found.

\section{Change over time in the effects of child gender and age}

\subsection{Child gender}

Differences found between boys and girls in their time in a number of activities (see Tables III and IV) were largely in line with previous research (e.g. Maudlin and Meeks, 1990). Girls spent more time doing homework, housework, shopping, hobbies, and socialising (both at home and elsewhere). They also spent less time in total home-indoor activities, though more time in personal activities (also predominantly at home). Boys spent more time in screenbased activities, in sport, and in out-of-home/outdoor play.

The models including interactions between survey year and gender showed that there were different trends for boys and girls for some activities, but these were restricted to home/indoor activities (model results not reported). Specifically, there were significant interaction effects between gender and survey year for the following four home/indoor activities: homework, housework, hobbies, and screen-based activities. To consider the substantive import of these findings, Figure I reports predicted minutes for boys and girls in 1975, 2000, and 2015 from models with significant interactions effects, with the vertical bars indicating 95\% confidence intervals (non-overlapping confidence intervals indicate statistically significant differences between boys and girls). 
Both boys and girls increased their homework time, but girls outpaced boys in this regard such that a significant gender gap in time doing homework emerged in 2000 and sustained in 2015. This emerging and persistent gender difference in homework aligns with gender differences in secondary school attainment in the UK, where girls consistently outperform boys (Younger \& Warrington, 1996; DfE, 2014), and are more likely than boys to stay in full-time education at age 16 and be entered for A-levels, which are the main route to university in the UK (DfES, 2007).

At the same time as girls have become increasingly oriented towards their education, their time committed to housework decreased by a greater extent compared with boys (see also Hofferth, 2009). However, they continued to spend more time in housework than boys did in both 2000 and 2015, even though the gender gap narrowed significantly in these years. This echoes changes in the gender division of domestic labour found among adults over this period (Gershuny, 2000), and it could be that girls spend less time together with their mothers in this activity, or are taking a cue from changes in their mother's engagement in domestic work. However, the relative stability of significant gender differences from 2000 onwards, together with little change among boys between 1975 and 2015, suggests limited apparent change in gender norms relating to time in this activity for children.

\section{[FIGURE I ABOUT HERE]}

Among leisure activities, both boys and girls decreased their time in hobbies, but this decrease was greater for boys such that they spent less time in these activities than girls did in both 2000 and 2015, whereas there was no gender difference in 1975. Admittedly, this is a broad activity group, and these changes may relate to specific activities in this group, but 
further analysis is not possible because the 1975 survey does not provide much detail on the activities included in this measure. Lastly, boys spent more time in screen-based activities than girls in all three years, but the gender gap widened significantly between 2000 and 2015 (see Figure I). Analysis of trends in children's time in specific screen-based activities, and using technology, is taken up in a separate paper (Mullan, 2017). The findings serve here to highlight that it is among boys where increases in time in home/indoor activities, concentrated in time in screen-based activities, are most pronounced.

Gender remains a significant determinant of children's time use in the UK over the entire period considered here. There was no change in the strong effect of gender in the models for sport and play (with boys exceeding girls) and in the models for social activities and housework (with girls exceeding boys), marking these activities out as persistently gendered (see Table IV). Moreover, even in activities where there were differential trends for boys and girls, nowhere did gender cease to be a significant determinant of children's time use. In fact, the division of time at home between homework and screen-based activities is to some extent an emerging gender division of time with girls spending more time in the former and boys more time in the latter. It is striking that gender continues to mark children's daily lives in both old and new ways. The experience of gender as difference, at least through how time is spent, certainly remains a pervasive feature of daily life for children.

\subsection{Child age}

Like gender, age is a significant determinant of many aspects of children's time use (see Tables III and IV). Yet unlike gender, models including interactions between survey year and age reveal that trends in children's time use have altered substantially the relationship between age and children's time in many activities (model results not reported). To explore 
the implications of these results, Figure II reports predicted minutes for children in different age groups in 1975, 2000, and 2015 for nine activities where differential trends for children in different age groups were found, with the vertical bars indicating $95 \%$ confidence intervals (non-overlapping confidence intervals indicate statistically significant differences between age groups).

Homework time increases with age in all years, but the positive age gradient in homework increased significantly over time because, although it increased for all children, increases were greater for children 14-16 years. In contrast, a positive age gradient in both housework and paid work substantially diminished over time, with older children becoming more like their younger counterparts, again as the downward trend in both these activities was concentrated among children 14-16 years. The trends for paid work among early adolescents found here tally with a decline in older adolescents engaging in paid work (Conlon et al., 2015; Zick, 2010). It is reasonable to expect children to assume increased responsibilities at home and elsewhere as part of their development as they age, which was the case. This is declining over time, however, as differences in committed activities associated with age, reflecting growing responsibilities, are increasingly restricted to education-related activities only.

\section{[FIGURE II ABOUT HERE]}

Positive age gradients for time in sport, hobbies and out-of-home socialising, apparent in 1975, diminished or disappeared over time. There was no change in time in sport for children 14-16 years, but it did increase for younger children (especially among children 11-13 years) such that they have become more like their older counterparts over time. It is possible that the 
presence of adult supervision in organised sports may be a pertinent factor in these results in that concerns for children's safety, and the ensuing need for supervision, are most likely perceived higher for younger than older children. Time in hobbies decreased for all age groups, but this was greatest among children 14-16 years, such that there were no age differences in this activity in 2000 and 2015. Unlike time in hobbies, change in out-of-home socialising was entirely concentrated among children 14-16. Therefore, in this activity, older children have become more like their younger counterparts over time.

As time in out-of-home play decreased over time so too have age differences associated with time in this activity, primarily because younger children's time in this activity decreased to a greater extent than older children (albeit from a much higher level). However, the overriding pattern here is not so much about a homogenisation of time in play across age groups over time (as shown for sport, hobbies, and out-of-home socialising), but rather the steady disappearance of time in this activity for children in all age groups. Reports of the supposed disappearance of children's play have a long history (see Roberts, 1980: 26-39), and no doubt the nature of play changes, but these results nevertheless present a stark picture of decline in the amount of time children spend in an activity that is intimately tied to commonly shared understandings of what childhood is.

Finally, significant age differences emerged in children's time in screen-based activities. Compared with no difference in 1975, children 14-16 years spent 39 minutes more in screenbased activities than children $8-10$ years in 2015. This is interesting in light of the diminished relationship between age and children's time in hobbies and out-of-home socialising (noted above), suggesting some degree of displacement between these activities and screen-based activities for older children in particular. 
Taken together, these results show that the splitting of time at home between 1975 and 2000 toward more time in homework and screen-based activities, away from housework and hobbies, is concentrated among older children 14-16 years, with a compression of age differences in the latter and a widening of age differences in the former. Age remains a significant marker of the way in which children spend time at home/indoors, but for different activities at different points in time. On the other hand, decreases in time in out-ofhome/outdoor activities, especially between 2000 and 2015, coincide with a compression of age-related differences over time in all these activities. Screen-based activities therefore have emerged as a major site for age-based distinctions in children's leisure time, over a period when technology and the online world (as opposed to the outside world) have become increasingly central to the formation of identity in childhood and youth (Livingstone, 2009b).

\section{Conclusion and future research}

Children today appear to be leading less physically active, more home-based lives than in previous decades. Their time in screen-based activities has increased, and although time in sport did increase, time in play beyond the home decreased by a greater extent. Children's time doing homework also increased, though it is far from dominating their time outside school. Overall time at home increased, and time beyond the home decreased, but this was concentrated in the years between 2000 and 2015. These trends are consistent both with the influence of parental concerns for children's safety and the increasing importance of education in children's lives, but arguably it is rapid technological change over the past decade that exerts the strongest influence on change in children's daily lives. 
However, this study does not identify causal links between these factors and the changes in children's time use found here. Although the findings presented here broadly accord with arguments about change in children's daily lives over this period, further work is required to elucidate and test specific, possibly interconnecting, mechanisms that might link change in various aspects of children's time use to factors such as safety concerns and technological change. The present study nonetheless provides some basic empirical grounding for widely held views around how children's daily lives have changed over the past several decades. It also provides a fresh perspective on our understanding of change in children's daily life in showing, for the first time, the relative magnitudes of change in the time children spend in different activities throughout the day that can inform wider debates about change in children's daily lives. The results suggest that while significant trends towards more time in home/indoor activities are substantively important, relatively modest increases in children's average time in sport or outdoor play might see them in part reversed.

This research adds the UK to a small number of studies of trends in children's time use carried out in other countries. Change in children's time use in the UK is broadly similar to patterns found in the USA and Italy, though key differences in study deign and scope across countries hinder a more thorough comparison. Cross-national comparative analysis is a major component of time use research, but there is a serious dearth of cross-national studies of children's time use. The study of cross-national differences in children's time use has the potential to yield further insights into the way in which social contexts might influence children's daily lives.

This paper has a number of specific limitations. Due to a lack of data it was not possible to delineate trends throughout the 1980s and 1990s (nor prior to the 1970s), and we cannot 
conclude that change occurred specifically at the points in time observed here. Although we cannot address this, future endeavours can build on this research by continuing to collect data on children's time use to track future trends. The focus of this paper was on children's main activities, and future contributions should incorporate the social aspects of children's time use such as time with parents, family, and friends. Moreover, change in specific aspects of a child's day (e.g. time afterschool) merits closer inspection than was possible here. In addition, this paper has not touched on children's use of new technologies such as smartphones and tablets, which is the focus of a separate paper (Mullan, 2017). Lastly, the focus here was on gender and age differences in children's time use, and future work could probe further into the socio-economic differences in children's time use reported here.

\section{References}

Ben-Arieh, A. and Ofir, A. 2002 'Time for (more) time-use studies: Studying the daily activities of children', Childhood 9(2): 225-248.

Bianchi, S.M. and Robinson, J. 1997 'What did you do today? Children's use of time, family composition and the acquisition of social capital.' Journal of Marriage and Family, 59(2): 332-344.

Buckingham, D. 2011 The material child: growing up in consumer culture. Cambridge: Polity Press.

Carriero, R. 2006 'Children's time in Turin: 1979-2003.' Quaderni di Sociologia 42.

Conlon, G., Patrignani, P. and Mantovani, I. 2015 The death of the Saturday job: The decline in earning and learning amongst young people in the UK. London: London Economics. 
Dallman, J., Norton, K. and Norton, L. 2005 'Evidence for secular trends in children's physical activity behaviour' British Journal of Sports Medicine 39: 892-897.

DCMS 2014 Taking Part 2013/14 annual child report. London: Department for Culture Media \& Sport.

DfEE, 1998 Homework: Guidelines for primary and secondary schools. London: Department for Education and Employment: Standards and Effectiveness Unit.

DfES, 2007 Gender and education: The evidence on pupils in England. London: Department for Education and Skills.

DfE 2014 'GCSE and equivalent attainment by pupil characteristics in England 2012/13.' SFR 05/2014. London: Department for Education.

Ennew, J. 1994 'Time for children or time for adults' in J. Qvortrup, M. Bardy, G. Sgritta and H. Wintersberger (eds) Childhood matters: Social theory, practice and politics, Aldershot: Avebury.

Eurostat 2009 'Harmonised European time use surveys: 2008 guidelines’ Luxembourg: Office for Official Publications of the European Communities

Faulkner, G., Mitra, R., Buliung, R., Fusco, C., and Stone, M. 2015 ‘Children’s outdoor playtime, physical activity, and parental perceptions of the neighbourhood environment.' International Journal of Play 4(1): 84-97.

Finch, N. 2002 'Physical activity: Structured sport vs active play' in J. Bradshaw (ed) The well-being of children in the UK ( $1^{\text {st }}$ edition $)$, London: Save the Children.

Furedi, F. 2005 Culture of fear: Risk-taking and the morality of low expectation. London: Continuum.

Gershuny, J. 2000 Changing times: Work and leisure in postindustrial society. Oxford: Oxford University Press. 
Gill, T. 2007 No fear: growing up in a risk averse society. London: Calouste Gulbenkian Foundation.

Halsey, A.H. 2000 'Further and higher education' in A.H. Halsey and J. Webb (eds) Twentieth-century British social trends. Basingstoke: Macmillan Press Ltd.

Hillman, M., Adams, J. and Whitelegg, J. 1990 One false move: A study of children's independent mobility. London: Policy Studies Institute.

Hills, A.P., Andersen, L.B. and Byrne, N.M. 2011 'Physical activity and obesity in children’ British Journal of Sports Medicine 45: 866-870.

Hofferth, S.L. 2009 'Changes in American children's time - 1997 to 2003.' electronic Journal of Time Use Research 6(1): 26-47.

Hofferth, S.L. 2010 'Home media and children's achievement and behaviour.' Child Development, 81(5): 1598-1619.

Hofferth, S.L. and Sandberg, J.F. 2001 'How American children spend their time.' Journal of Marriage and Family 63(2): 295-308

James, A., Jenks, C. and Prout, A. 1998 Theorizing childhood. Cambridge: Polity Press.

Karsten, L. 2005 'It all used to be better? Different generations on continuity and change in urban children's daily use of space.' Children's Geographies 3(3): 275-290.

Kelly, P., Hood, S., and Mayall, B. 1998 'Children, parents and risk.' Health and Social Care in the Community, 6(1): 16-24.

Lacey, L. 2007 Street play: a literature review. London: Play England.

Larson, R.W. and Verma, S. 1999 'How children and adolescents spend time across the world: work, play, and developmental opportunities.' Psychological Bulletin, 25(6): 701-736.

Livingstone, S. 2002 Young people and new media: childhood and the changing media environment. London: Sage. 
Livingstone, S. 2009a 'Half a century of television in the lives of our children' The Annals of the American Academy of Political and Social Science 625: 151-163.

Livingstone, S. 2009b Children and the internet: Changing expectations, challenging realities. Cambridge: Polity Press.

Loebach, J. and Gilliland, J. 2016 'Neighbourhood play on the endangered list: examining patterns in children's local activity and mobility using GPS monitoring and qualitative GIS', Children's Geographies 14(5): 573-589.

Machin, S. and Vignoles, A. 2006 'Education policy in the UK', Centre for the Economics of Education Discussion Paper no. 0057. London: Centre for the Economics of Education, London School of Economics.

Marshall, S.J., Gorely, T. and Biddle, S.J.H. (2006). 'A descriptive epidemiology of screen-based media use in youth: A review and critique.' Journal of Adolescence, 29(3): 333-349.

Maudlin, T. and Meeks, C.B. 1990 'Sex differences in children time use.' Sex Roles 22(9/10): 537-554

McNeish, D. and Roberts, H. 1995 Playing it safe: today's children at play. Ilford: Bernardo's

Mullan, K. 2017 'Technology and children's screen-based activities in the UK: The story of the millennium so far.' Child Indicators Research, Published online: 14 November 2017. https://doi.org/10.1007/s12187-017-9509-0

Mullis, I.V.S., Martin, M.O., Gonzalez, E.J., and Chrostowski, S.J. 2005 TIMSS 2003 International Mathematics Report. Boston: TIMSS \& PIRLS International Study Center, Lynch School of Education, Boston College. 
Mullis, I.V.S., Martin, M.O., Foy, P., and Hooper, M. 2015 TIMSS 2015 International Mathematics Report. Boston: TIMSS \& PIRLS International Study Center, Lynch School of Education, Boston College.

NICE 2009 Promoting physical activity, active play and sport for pre-school and school-age children and young people in family, pre-school, school and community settings. London: National Institute for Health and Clinical Excellence.

Oakley, A. 2015 Sex, gender and society. Farnham: Ashgate.

Ofcom. 2015 Children and parents: media use and attitudes report. London: Ofcom.

Ofcom. 2016 Children and parents: media use and attitudes report. London: Ofcom.

ONS. 2002 Family spending: A report on the 2000-01 Family Expenditure Survey. London: The Stationary Office.

ONS. 2009 Social Trends 39. Basingstoke: Palgrave Macmillan.

ONS. 2014 Family spending: A reports on the living costs and food survey 2013. London: The Stationary Office.

ONS. 2015a Participation rates in the UK Labour Market. Newport: The Office for National Statistics.

ONS. 2015b Internet access - Households and individuals. Newport: The Office for National Statistics.

ONS. 2016 Families and households in the UK: 2016. Newport: The Office for National Statistics.

OPCS. 1974 The General Household Survey. London: The Stationary Office.

Palmer, S. 2007 Toxic childhood: how the modern world is damaging our children and what we can do about it. London: Orion.

PHE 2013 How heathy behaviour supports children's wellbeing. London: Public Health England. 
Prout, A. 2005 The Future of Childhood. London: RoutledgeFalmer.

Roberts, A. 1980 Out to play: the middle years of childhood. Aberdeen: Aberdeen University Press.

Robinson, J.P. 1985 'The validity and reliability of diaries versus alternative time use measures.' In Juster, F.T. and Stafford, F.P. (eds) Time, goods and wellbeing. Ann Arbor: University of Michigan.

Shaw, B., Watson, B., Frauendienst, B., Redecker, A., Jones, t. with Hillman, M. 2013 'Children's independent mobility: a comparative study in England and German (10972010). London: Policy Studies Institute.

Valentine, G. 1997 '”Oh yes I can.” “Oh no you can't.”: Children and parents' understandings of kids' competence to negotiate public space safely', Antipode 29(1): 65-89.

Valentine, G. 2004 Public space and the culture of childhood. Aldershot: Ashgate.

Valentine, G. and McKendrick, J. 1997 ‘Children’s outdoor play: Exploring parental concerns about children's safety and the changing nature of childhood', GeoForum 28(2): 219-235.

Weston, P. 1999 Homework: learning from practice. London: The Stationary Office.

Wyness, M.G. 2006 Childhood and society: An introduction to the sociology of childhood. Basingstoke: Palgrave Macmillan.

Younger, M. and Warrington, M. 1996 'Differential achievement of girls and boys at GCSE: some observations from the perspective of one school.' British Journal of Sociology of Education 17(3): 299-313.

Zick, C.D. 2010 'The shifting balance of adolescent time use.' Youth \& Society 41(4): 569596. 
Table I. Measures of children's time use: home/indoor and out-of-home/outdoor

\begin{tabular}{ll}
\hline Home/indoor activities & Out-of-home/outdoor activities \\
\hline Homework and study (Homework) & Paid work (Paid)* \\
\hline $\begin{array}{l}\text { Housework and care (Housework) } \\
\text { Includes cleaning, cooking, gardening, } \\
\text { child and adult care }\end{array}$ & $\begin{array}{c}\text { Shopping (Shopping)* } \\
\text { Includes housework/care not at home }\end{array}$ \\
\hline $\begin{array}{l}\text { Socialising } \\
\text { Includes talking, interacting with others, } \\
\text { parties and social events, and relaxing/rest }\end{array}$ & $\begin{array}{c}\text { Socialising and entertainment (Socialising)* } \\
\text { Includes cinema, sporting events, trips, } \\
\text { outings, and activities included in } \\
\text { home/indoor socialising home taking } \\
\text { place outside the home }\end{array}$ \\
\hline $\begin{array}{l}\text { Play and games (Play) } \\
\text { Includes general play alone and } \\
\text { with others and games (but not videogames) }\end{array}$ & $\begin{array}{c}\text { Play and games (Play)* } \\
\text { Includes general play alone and } \\
\text { with others and games (but not } \\
\text { videogames) }\end{array}$ \\
\hline $\begin{array}{l}\text { Hobbies, arts, music, reading (Hobbies) } \\
\text { Includes activities like collecting, visual, }\end{array}$ & $\begin{array}{c}\text { Sport and exercise (Sport)* } \\
\text { Includes cycling, walking, } \\
\text { solo and team sports }\end{array}$ \\
\hline $\begin{array}{l}\text { Screen-based activities } \\
\text { TV, videogames, using computers }\end{array}$ & $\begin{array}{c}\text { Religious and civic activities (Civic)* } \\
\text { Includes time at church, and time } \\
\text { in voluntary activities }\end{array}$ \\
\hline Total home/indoor activities & $\begin{array}{c}\text { Total out-of-home/outdoor activities } \\
\text { Necessary activities }\end{array}$ \\
$\begin{array}{l}\text { Sleeping, eating, personal activities } \\
\text { Notes: * Includes travel associated with activity at school* } \\
\text { Includes time in classes, and other } \\
\text { activities at school including break times }\end{array}$ \\
\hline
\end{tabular}

Notes: * Includes travel associated with activity 
Table II. Characteristics of the sample included in the analysis

\begin{tabular}{lccr}
\hline & $\mathbf{1 9 7 5}$ & $\mathbf{2 0 0 0}$ & $\mathbf{2 0 1 5}$ \\
\hline Total number of school days & 1,220 & 1,043 & 660 \\
Total number of non-school days & 1,845 & 1,968 & 1,223 \\
Total number of diaries & 3,065 & 3,011 & 1,883 \\
Total number of children & 533 & 1,548 & 958 \\
\hline Boy (\%) & 52 & 51 & 50 \\
Girl (\%) & 48 & 49 & 50 \\
\hline 8-10 years (\%) & 39 & 37 & 34 \\
$11-13$ years (\%) & 34 & 35 & 33 \\
14-16 years (\%) & 27 & 29 & 33 \\
\hline Average number in household & 5.1 & 4.4 & 4.3 \\
\hline Two-parent family (\%) & 96 & 78 & 78 \\
Lone-mother family (\%) & 4 & 22 & 22 \\
\hline Mother: Not employed (\%) & 34 & 31 & 32 \\
Mother: Employed (\%) & 66 & 69 & 68 \\
\hline Mother: Compulsory schooling only (\%) & 73 & 60 & 63 \\
Mother: Post-compulsory schooling (\%) & 27 & 40 & 37 \\
\hline
\end{tabular}


Table III. OLS results for home/indoor activities

\begin{tabular}{|c|c|c|c|c|c|c|c|c|}
\hline & \multicolumn{8}{|c|}{ Home/indoor activities } \\
\hline & Homework & Housework & Play & Socialising & Hobbies & $\begin{array}{c}\text { Screen-based } \\
\text { activities }\end{array}$ & Total $^{1}$ & $\begin{array}{c}\text { Sleep/ } \\
\text { personal }\end{array}$ \\
\hline 2000 & $15.1 * * *$ & $-9.3 * * *$ & -1.0 & -1.5 & $-16.9 * * *$ & $12.8^{*}$ & 2.8 & $-7.5^{*}$ \\
\hline 2015 & $17.3 * * *$ & $-8.6 * * *$ & $-6.8 * *$ & $4.8^{*}$ & $-19.4 * * *$ & $22.4 * * *$ & 11.9 & $10.4 * *$ \\
\hline Girl & $6.9 * * *$ & $13.6 * * *$ & -3.4 & $7.5^{* * *}$ & $7.9 * * *$ & $-46.6 * * *$ & $-12.8^{*}$ & $14.9 * * *$ \\
\hline $11-13$ years & $9.6 * * *$ & $10.5 * * *$ & $-28.6 * * *$ & $7.0 * * *$ & $6.1 * *$ & $21.0 * * *$ & $24.1 * * *$ & $-48.5 * * *$ \\
\hline $14-16$ years & $23.1 * * *$ & $17.8 * * *$ & $-49.9 * * *$ & $15.8 * * *$ & $11.3 * * *$ & $17.4^{* *}$ & $32.1 * * *$ & $-74.5 * * *$ \\
\hline Lone mother household & $-6.7 * * *$ & $-4.0 *$ & -3.2 & -0.2 & -3.5 & 2.2 & $-15.0 *$ & $9.3^{*}$ \\
\hline Mother employed & -1.5 & 3.1 & 0.4 & -1.7 & 1.9 & 2.1 & 3.0 & $-11.5^{* * *}$ \\
\hline Mother post-compulsory education & $10.8 * * *$ & 2.2 & 2.4 & -0.8 & $8.8 * * *$ & $-17.5 * * *$ & 2.8 & 1.7 \\
\hline Household size & -0.7 & $1.8 * *$ & -0.8 & 0.7 & -0.2 & -1.1 & -0.1 & -1.2 \\
\hline Non-school day & $-9.8 * * *$ & $18.4 * * *$ & $28.6 * * *$ & $12.6 * * *$ & $21.4 * * *$ & $80.1 * * *$ & $153.2 * * *$ & $86.4 * * *$ \\
\hline Intercept & -0.9 & $5.7 * *$ & $41.2 * * *$ & 3.2 & $17.0 * * *$ & $131.7 * * *$ & $205.9 * * *$ & $719.1 * * *$ \\
\hline Adjusted R-Square & 0.11 & 0.10 & 0.13 & 0.05 & 0.07 & 0.12 & 0.20 & 0.22 \\
\hline
\end{tabular}

Notes: $\mathrm{N}=7,958 ; * * * \mathrm{p}<.001 ; * * \mathrm{p}<.01 ; * \mathrm{p}<.05 ; 1$. Includes time when no main activity reported, and excluding sleep/personal time; Statistical tests use cluster robust standard errors; reference categories: boy, 8-10 years, two-parent household, mother not in paid work, mother completed compulsory schooling only, average household size, diary completed on a non-school day. Day weight applied. 
Table IV. OLS results for out-of-home/outdoor activities

\begin{tabular}{|c|c|c|c|c|c|c|c|c|}
\hline & \multicolumn{8}{|c|}{ Out-of-home/outdoor activities } \\
\hline & Paid & Shopping & Play & Socialising & Sport & Civic & Total $^{1}$ & School \\
\hline 2000 & -4.9 & $15.5 * * *$ & $-17.3 * * *$ & -8.8 & $14.1 * * *$ & $6.1 * * *$ & 5.6 & -0.8 \\
\hline 2015 & $-8.4 * *$ & $7.6 * * *$ & $-29.4 * * *$ & $-14.7 * *$ & $17.4 * * *$ & $4.1 * *$ & $-21.0 * *$ & -1.3 \\
\hline Girl & -3.1 & $10.7 * * *$ & $-6.5^{*}$ & $15.6^{* * *}$ & $-18.7 * * *$ & $2.3^{*}$ & 0.7 & -2.8 \\
\hline $11-13$ years & $2.7 *$ & 0.4 & $-13.4 * * *$ & $9.7 *$ & $8.8 * * *$ & 1.0 & 8.2 & $16.2 * * *$ \\
\hline 14-16 years & $26.8 * * *$ & 0.5 & $-34.0 * * *$ & $26.9 * * *$ & $9.2 * * *$ & 2.3 & $30.0 * * *$ & $12.4 * * *$ \\
\hline Lone mother household & -2.9 & $-4.2 *$ & $7.2 *$ & $11.8 *$ & -0.3 & -2.1 & 10.4 & $-4.7 *$ \\
\hline Mother employed & $5.7 * *$ & 2.0 & -2.7 & 2.3 & 1.4 & 0.2 & 8.0 & 0.5 \\
\hline Mother post-compulsory education & -3.4 & 0.5 & $-8.6^{* * *}$ & -6.0 & 0.8 & $4.7 * * *$ & $-12.7^{*}$ & $8.3 * * *$ \\
\hline Household size & -1.2 & $-1.9 * * *$ & $3.6 * *$ & -0.2 & 0.8 & 0.7 & 2.0 & -0.7 \\
\hline Non-school day & $9.8 * * *$ & $35.7 * * *$ & $32.5 * * *$ & $82.2 * * *$ & $29.0 * * *$ & $4.4 * * *$ & $196.0 * * *$ & $-435.5 * * *$ \\
\hline Intercept & -0.3 & $-4.7 *$ & $47.1 * * *$ & $24.9 * * *$ & $9.4^{* *}$ & 2.3 & $80.9 * * *$ & $434.1 * * *$ \\
\hline Adjusted R-Square & 0.05 & 0.09 & 0.10 & 0.10 & 0.06 & 0.01 & 0.27 & 0.93 \\
\hline
\end{tabular}

Notes: $\mathrm{N}=7,958 ; * * * \mathrm{p}<.001 ; * * \mathrm{p}<.01 ; * \mathrm{p}<.05 ; 1$. Includes time when no main activity reported, and excluding time at school; Statistical tests use cluster robust standard errors; reference categories: boy, 8-10 years, two-parent household, mother not in paid work, mother completed compulsory schooling only, average household size, diary completed on a non-school day. Day weight applied. 
Figure I: Gender differences in predicted minutes (with 95\% confidence intervals) in homework, housework, hobbies, and screen-based activities in 1975, 2000, and 2015

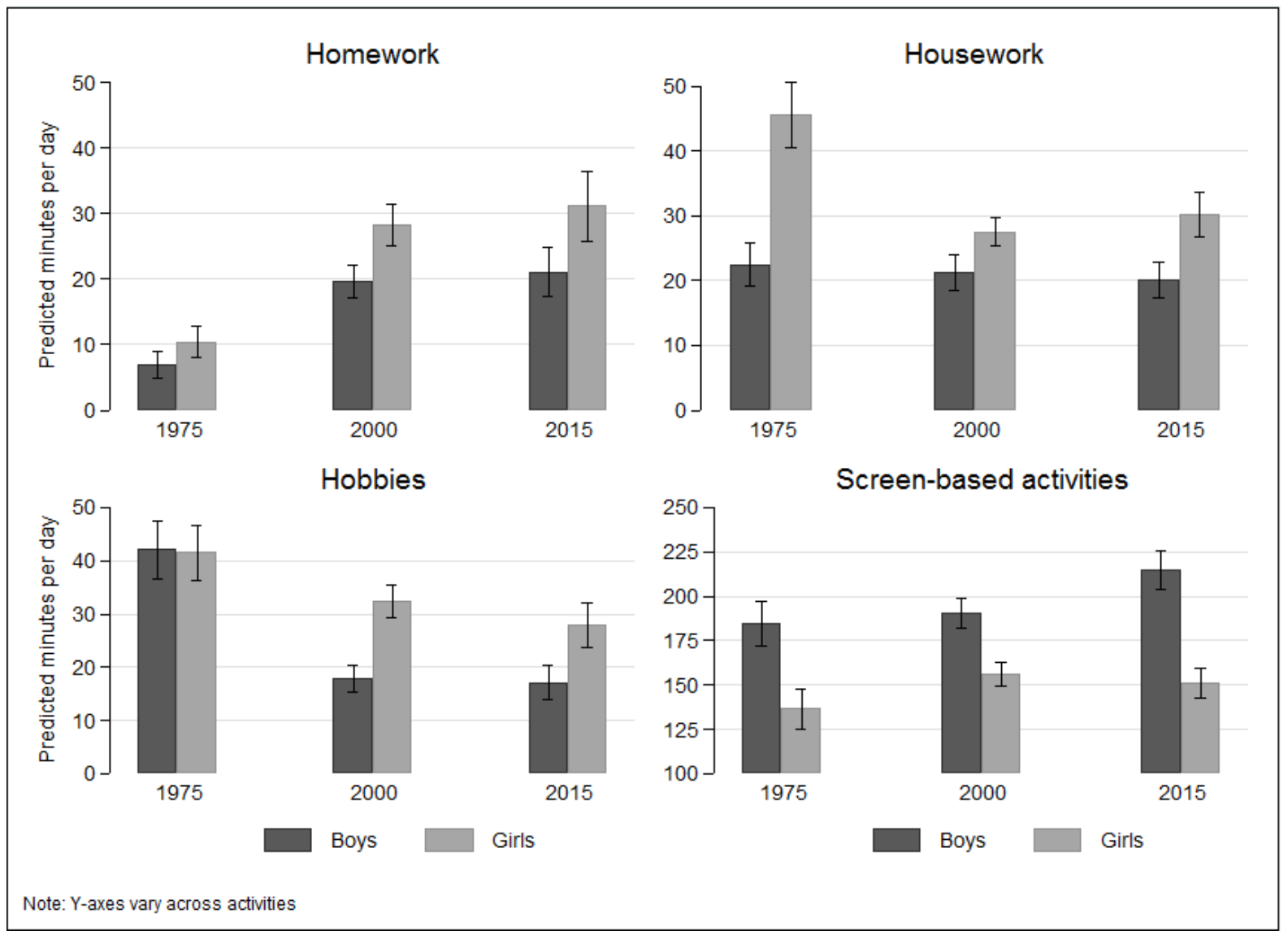


Figure II: Age group differences in predicted minutes (with 95\% confidence intervals) in homework, housework, paid work, sport, hobbies, out-of-home/outdoor socialising, out-ofhome/outdoor play, and screen-based activities in 1975, 2000, and 2015

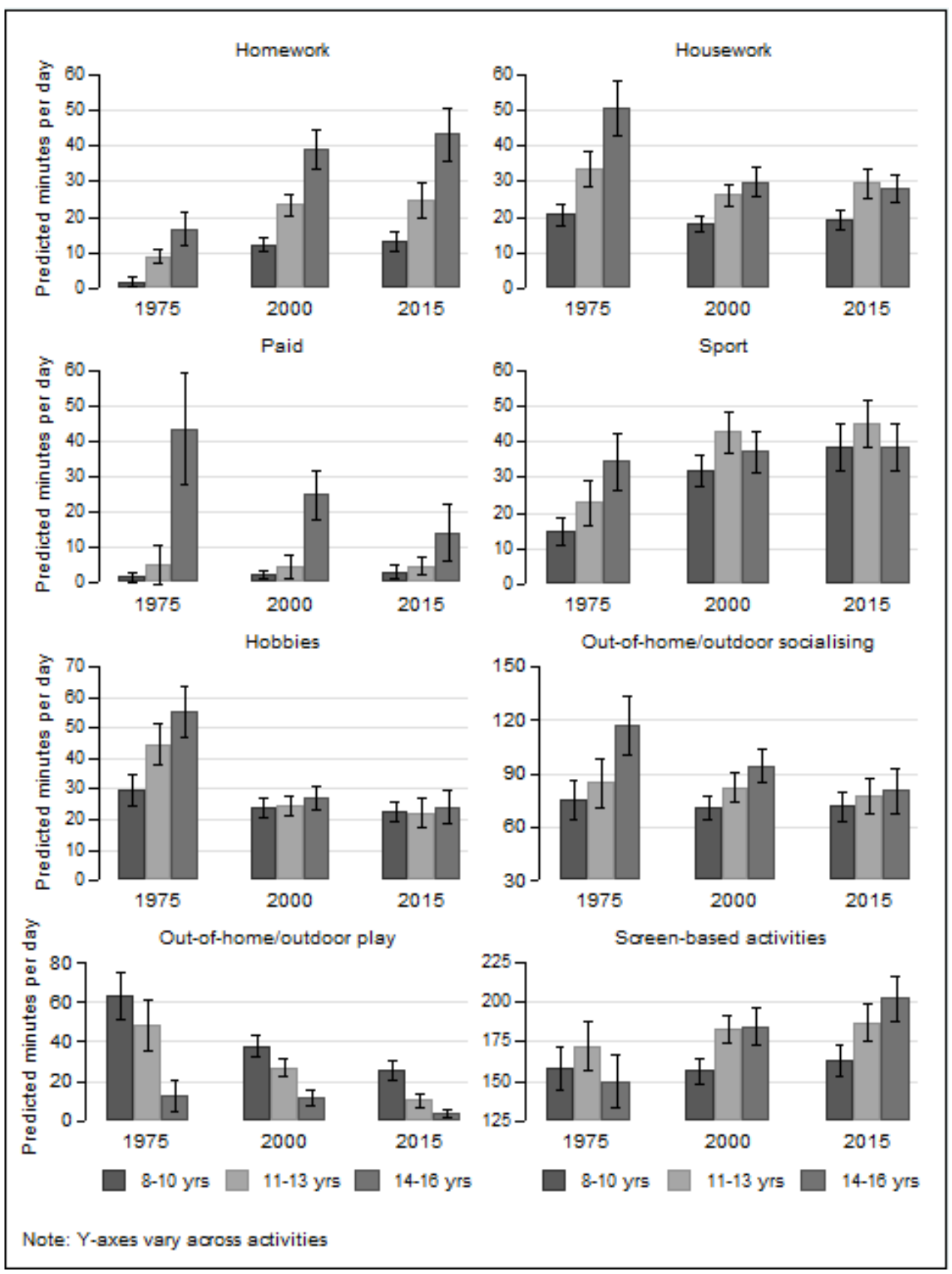

${ }^{i}$ Details of the coder reliability tests carried out in UKTUS 2000 and 2015, along with information about survey administration, are given in the technical reports provided with the data deposited in the UK Data Archive. 